\title{
Pengaruh Pesan Persuasif Media Sosial LINE Terhadap Brand Resonance (Survei Pelanggan Starbucks Tangerang)
}

\author{
Andini Putri Apriani, Roswita Oktavianti \\ Andini.915120190@stu.untar.ac.id,roswitao@fikom.untar.ac.id \\ Fakultas Ilmu Komunikasi Universitas Tarumanagara
}

\begin{abstract}
This research discusses about the effect of persuasive social media Line messages to brand resonance on Starbucks Tangerang's customers. The theory used in this research are persuasive messages and brand resonance. The method of this research is quantitative using associative explanative survey techniques as the basis of the research. The sampling technique used in this research is probability sampling, where sampling provides the same opportunity for each population to be selected as a sampel. The result of this research indicates that there is a very strong effect from the persuasive messages of social media on brand resonance. The results of the determination test show that $77.8 \%$ of the persuasive messages variables can influence the brand resonance variables, while the rest $22.2 \%$ are influenced by other variables.
\end{abstract}

Keyword: Persuasive Messages, Social Media, Brand Resonance

\begin{abstract}
Abstrak
Penelitian ini membahas pengaruh pesan persuasif media sosial Line terhadap brand resonance terhadap pelanggan Starbucks Tangerang. Konsep yang digunakan pada penelitian ini adalah pesan persuasif dan brand resonance. Metode penelitian yang digunakan pada penelitian ini adalah metode kuantitatif dengan menggunakan teknik survei eksplanatif asosiatif sebagai dasar penelitian. Teknik sampling yang digunakan adalah probability sampling dimana pengambilan sampel memberikan peluang yang sama bagi setiap unsur populasi untuk dipilih menjadi unsur sampel. Penelitian ini menggunakan 117 responden sebagai sampel. Hasil penelitian ini menunjukan bahwa terdapat pengaruh yang sangat kuat dari pesan persuasif media sosial terhadap brand resonance. Hasil uji determinasi menunjukkan $77.8 \%$ variabel pesan persuasif dapat memberikan pengaruh terhadap variabel brand resonance, sedangkan sisanya $22.2 \%$ dipengaruhi oleh variabel-variabel lain.
\end{abstract}

Kata Kunci: Pesan Persuasif, Media Sosial Line, Brand Resonance 


\section{Pendahuluan}

Pesan persuasif digunakan untuk menjual ide atau gagasan kepada orang lain, memberi saran agar prosedur operasional lebih efisien, mengumpulkan suatu dukungan untuk kegiatan tertentu, dan untuk meminta bantuan dana bagi pembiayaan suatu proyek tertentu. Pesan persuasif bertujuan untuk mempengaruhi audiens yang cenderung mempertahankan ide, atau gagasannya. Pesan persuasif umumnya lebih lama dan lebih rinci (Purwanto, 2011:164).

Little John mengatakan pesan persuasif dianggap sebagai salah satu cara untuk mengalihkan gagasan dan aksi dengan mengatur motif kedalam tujuan tertentu (dalam Ritonga, 2006:5). Menurut Vik \& Gilsdorf pesan persuasif adalah pesan yang mempunyai tujuan untuk mengubah pendapat, sikap, kepercayaan bahkan perilaku seseorang atau organisasi (Haryani, 2001:141). Ritonga juga menjelaskan bahwa pesan dapat berwujud symbol seperti kata-kata yang diucapkan, maupun ilustrasi. Lalu pesan juga dapat dikirimkan langsung dari komunikator ke komunikan melalui media atau penginterpretasian pesan persuasif sebagai cara untuk mengalihkan gagasan dan aksi dengan tujuan tertentu. (Ritonga, 2005:5).

Generasi muda meemiliki akses yang tinggi terhadap media sosial (Oktavianti \& Loisa, 2017). Line merupakan sebuah alat pengiriman pesan tanpa biaya yang dapat digunakan pada berbagai platform. Line memiliki fungsinya yaitu untuk berkomunikasi antara individu serta kelompok. Beberapa fitur Line antara lain free call, sticker, video call hingga Line Today yang berisikan tentang kejadian-kejadian yang terjadi saat ini (Priansa, 2017:370).

Keller memperkenalkan model Consumer Based Brand Equity, dimana model ini membentuk enam urutan brand building blocks yang menjadi Brand Pyramid salah satu nya yaitu Brand Resonance (Keller, 2013:80).

Tahap terakhir dalam model yang fokus pada hubungan terakhir antara customer terhadap suatu brand adalah brand resonance. Brand resonance menggambarkan hubungan dan tingkatan yang mana customer rasakan selaras terhadap suatu brand (Keller, 2013:92).

Brand resonance adalah karakteristik dari suatu intensitas atau kedalaman ikatan psikologis yang customers rasakan seperti rasa senang, bangga, sikap loyal dan keterikatan yang terjadi antara konsumen dengan suatu brand. Keller membagi menjadi empat kategori sebagai penyusun brand resonance yaitu behavioral loyalty (loyalitas perilaku), attitudinal attachment (sikap ketertarikan), sense of community (perasaan masyarakat) dan active engagement (pengikatan/tindakan aktif) (Keller, 2013:92-93).

Pada era modern saat ini, banyak coffee shop bermunculan yang bersaing secara ketat untuk menarik perhatian pelanggan, salah satunya adalah Starbucks. Starbucks merupakan salah satu coffee shop yang mempunyai lebih dari 355 gerai di seluruh Indonesia. Selain dengan berkembangnya zamannya, Starbucks tidak hanya memanjakan pelanggannya dengan menyediakan kopi terbaik tetapi juga Starbucks menyedikan sandwich, kue dan lainnya untuk menemani pelanggannya menikmati kopi (Partner Starbucks). 


\section{Metode Penelitian}

Metode penelitian yang digunakan pada penelitian ini adalah metode kuantitatif dengan menggunakan teknik survei eksplanatif asosiatif sebagai dasar penelitian. Teknik sampling yang digunakan adalah probability sampling dimana pengambilan sampel memberikan peluang yang sama bagi setiap unsur populasi untuk dipilih menjadi unsur sampel. Pengumpulan data dengan menyebarkan kuesioner kepada 117 pelanggan Starbucks di Tangerang.

Sumber data premier yang digunakan oleh penulis adalah kuesioner yang telah diisi oleh pelanggan di Starbucks Tangerang. Penulis menggunakan uji validitas. Uji validitas adalah kesamaan atau kesesuaian antara data yang terkumpul dengan data yang sesungguh nya terjadi pada objek yang diteliti (Sugiyono, 2010:121).

Uji reliabilitas untuk mengetahui bahwa data yang diperoleh valid atau tidak valid. Reliabilitas adalah alat untuk mengukur suatu kuisioner yang merupakan indikator dari variabel. Suatu alat ukur dikatakan memiliki reliabilitas apabila dipergunakan berkali-kali oleh peneliti yang sama atau peneliti lain tetap memberikan hasil yang sama (Rakhmat, 2016:58). Dari pengujian reliabilitas terhadap 14 butir variabel pesan persuasif, didapat nilai Cronbach's Alpha sebesar 0,947 yang berarti butir-butir pesan persuasif tersebut reliabel karena nilai Cronbach's Alpha > 0,7. 10 butir variabel brand resonance, didapat nilai Cronbach's Alpha sebesar 0,911 yang berarti butir-butir brand resonance tersebut reliabel karena nilai Cronbach's Alpha > 0,7. Ini menunjukkan bahwa setiap variabel dinyatakan reliabel.

Sedangkan untuk mengetahui apakah data tersebut memenuhi uji normalitas, penulis menggunakan normal P-P Plot yang pada prinsipnya dapat dilihat dari penyebaran titik sumbu diagonal grafik. Uji normalitas dilakukan untuk mengetahui apakah distribusi sebuah data yang didapatkan mengikuti atau mendekati hukum sebaran data normal baku dari Gauss. Hasil uji normalitas dapat dilihat dari nilai sig (p) Kolmogorov Smirnov dengan ketentuan sebaran data normal bila : p > 0,05 dan sebaran data tidak normal bila : p $<0,005$ (Nisfiannoor, 2013). Berdasarkan hasil pengolahan data dari uji normalitas, didapatkan nilai sig (p) Kolmogorov Smirnov sebesar 0,394 >0,05 untuk variabel brand resonance, sehingga dapat disimpulkan bahwa distribusi data variabel brand resonance adalah normal.

Teknik pengolahan data dan analisis data menggunakan uji koefisien korelasi dan determinasi, uji regresi linear sederhana dan uji T. Uji analisis koefisien korelasi bertujuan untuk mengukur seberapa kuat pengaruh hubungan variabel independent terhadap variabel dependent, sedangkan uji koefisien determinasi digunakan untuk melihat seberapa besar persentase variabel independent yang dapat berpengaruh terhadap variabel dependent.

\section{Hasil Temuan dan Diskusi}

\section{1) Uji Validitas}

\begin{tabular}{ccc} 
Tabel 1 & \\
& \multicolumn{2}{c}{ Validitas Variabel Pesan Persuasif } \\
\hline X & $\begin{array}{c}\text { Corrected Item- } \\
\text { Total Correlation }\end{array}$ & Keterangan \\
& 0.702 & Valid \\
PP1 & 0.765 & Valid \\
PP2 & 0.740 & Valid
\end{tabular}




\begin{tabular}{ccc}
\hline $\mathrm{X}$ & $\begin{array}{c}\text { Corrected Item- } \\
\text { Total Correlation }\end{array}$ & Keterangan \\
\hline PP4 & 0.763 & Valid \\
PP5 & 0.763 & Valid \\
PP6 & 0.703 & Valid \\
PP7 & 0.603 & Valid \\
PP8 & 0.777 & Valid \\
PP9 & 0.716 & Valid \\
PP10 & 0.749 & Valid \\
PP11 & 0.777 & Valid \\
PP12 & 0.700 & Valid \\
PP13 & 0.777 & Valid \\
PP14 & 0.700 & Valid \\
\hline
\end{tabular}

Hasil uji validitas terhadap 14 butir pernyataan dari variabel $\mathrm{X}$ yaitu pesan persuasif, memiliki nilai $r$ hitung $>0.200$ dinyatakan valid.

\section{Tabel 2}

Validitas Variabel Brand Resonance

\begin{tabular}{ccc}
\hline Y & $\begin{array}{c}\text { Corrected Item- } \\
\text { Total Correlation }\end{array}$ & Keterangan \\
\hline BR1 & 0.677 & Valid \\
BR2 & 0.376 & Valid \\
BR3 & 0.631 & Valid \\
BR4 & 0.509 & Valid \\
BR5 & 0.665 & Valid \\
BR6 & 0.819 & Valid \\
BR7 & 0.819 & Valid \\
BR8 & 0.798 & Valid \\
BR9 & 0.790 & Valid \\
BR10 & 0.774 & Valid \\
\hline
\end{tabular}

hasil uji validitas terhadap 14 butir pernyataan dari variabel Y yaitu brand resonance, memiliki nilai $r$ hitung $>0.200$ dinyatakan valid.

\section{2) Uji Reliabilitas}

\begin{tabular}{cr} 
Tabel 3 \\
Reliabilitas Pesan Persuasif \\
\hline \multicolumn{2}{c}{ Reliability Statistics } \\
\hline $\begin{array}{c}\text { Koefisien Alpha N of Items } \\
\text { (Cronbarch) } \\
.947\end{array}$ \\
\hline
\end{tabular}

Dari 14 butir variabel pesan persuasif, diperoleh Koefisien Alpha sebesar 0,947 yang berarti butir-butir pesan persuasif tersebut reliabel karena nilai Koefisien Alpha (Cronbarch) $>0,7$. 


\section{Tabel 4}

Reliabilitas Brand Resonance Reliability Statistics

\begin{tabular}{rr}
\hline $\begin{array}{r}\text { Koefisien Alpha } \\
\text { (Cronbarch) }\end{array}$ & $\mathrm{N}$ of Items \\
.911 & 10
\end{tabular}

Dari 10 butir variabel brand resonance, diperoleh Koefisien Alpha sebesar 0,911 yang berarti butir-butir brand resonance tersebut reliabel karena nilai Koefisien Alpha (Cronbarch) > 0,7.

\section{3) Uji Normalitas}

Tabel 5

Uji Normalitas

One-Sample Kolmogorov-Smirnov Test

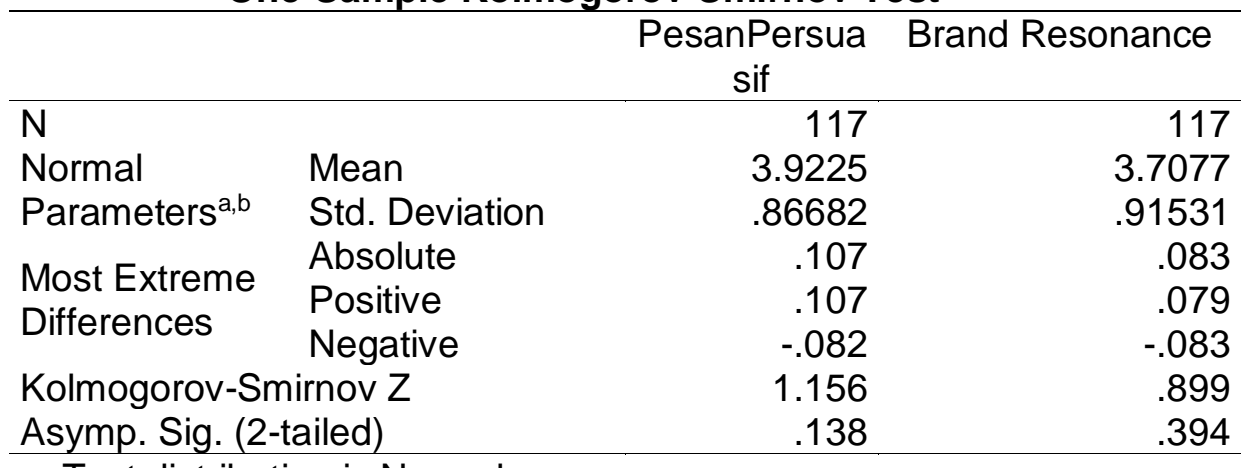

a. Test distribution is Normal.

b. Calculated from data.

Didapatkan nilai sig (p) Kolmogorov Smirnov sebesar 0,394 >0,05 untuk variabel brand resonance, sehingga dapat disimpulkan bahwa distribusi data variabel brand resonance adalah normal.

\section{4) Uji Koefisien Korelasi dan Determinasi}

Tabel 6

\section{Uji Koefisien Korelasi dan Determinasi}

Model Summary ${ }^{\mathbf{b}}$

\begin{tabular}{lrrrrr}
\hline $\begin{array}{l}\text { Mode } \\
\text { I }\end{array}$ & $\mathrm{R}$ & $\begin{array}{c}\mathrm{R} \\
\text { Square }\end{array}$ & $\begin{array}{c}\text { Adjusted R } \\
\text { Square }\end{array}$ & $\begin{array}{c}\text { Std. Error of the } \\
\text { Estimate }\end{array}$ & Durbin-Watson \\
\hline 1 & $\begin{array}{rrrrr}882 \\
\text { a }\end{array}$ & .778 & .770 & .43882 & 1.941
\end{tabular}

a. Predictors: (Constant), Action, Attention, Desire, Interest

b. Dependent Variable: Brand Resonance

Nilai koefisien korelasi(R) dari variabel $\mathrm{X}$ pesan persuasif terhadap variabel $\mathrm{Y}$ brand resonance sebesar 0.882 karena hasil uji koefisien korelasi berada di rentang 0,80 - 1,000 maka dapat disimpulkan bahwa pengaruh antara pesan persuasif terhadap brand resonance adalah sangat kuat. 
Nilai koefisien determinasi pada tabel $\mathrm{R}$ square sebesar 0,778 menunjukkan bahwa $77.8 \%$ brand resonance dipengaruhi oleh pesan persuasif sementara sisanya $22,2 \%$ dipengaruhi oleh variabel-variabel lain.

\section{5) Regresi Linear Sederhana}

\begin{tabular}{|c|c|c|c|c|c|c|}
\hline & $\mathbf{R e}$ & $\begin{array}{r}\text { Tabe } \\
\text { resi Linear } \\
\text { Coeffici }\end{array}$ & derhana & & & \\
\hline \multirow[t]{2}{*}{ Model } & \multicolumn{2}{|c|}{$\begin{array}{c}\text { Unstandardized } \\
\text { Coefficients }\end{array}$} & \multicolumn{2}{|l|}{$\begin{array}{c}\text { Standardized } \\
\text { Coefficients }\end{array}$} & \multirow[t]{2}{*}{$t$} & \multirow[t]{2}{*}{ Sig. } \\
\hline & $B$ & Std. Error & Beta & & & \\
\hline \multirow{2}{*}{$\begin{array}{l}\text { (Constant) } \\
\text { PesanPersua } \\
\text { sif }\end{array}$} & .277 & .222 & & & \multirow{2}{*}{$\begin{array}{r}1.251 \\
15.85 \\
0\end{array}$} & .214 \\
\hline & .875 & .055 & & .828 & & .000 \\
\hline
\end{tabular}

a. Dependent Variable: Brand Resonance

Nilai sebesar 0.277 menyatakan konstanta dari fungsi regresi yang menunjukkan bahwa jika tidak ada kenaikan variabel $\mathrm{X}$ yaitu pesan persuasif, maka variabel Y yaitu brand resonance akan mencapai 0.277. Setiap ada penambahan 1 angka atau perubahan variabel $\mathrm{X}$ yaitu pesan persuasif, maka variabel $\mathrm{Y}$ yaitu brand resonance akan mengalami peningkatan sebesar 0.875 .

\section{6) Uji T}

\begin{tabular}{|c|c|c|c|c|c|}
\hline & & $\begin{array}{r}\text { Tabe } \\
\text { Uji } \\
\text { Coeffici }\end{array}$ & $\begin{array}{l}8 \\
\text { nts }^{a} \\
\end{array}$ & & \\
\hline Model & $\begin{array}{r}\text { Unstanc } \\
\text { Coeffi }\end{array}$ & $\begin{array}{l}\text { rdized } \\
\text { ents }\end{array}$ & Standardized Coefficients & $\mathrm{t}$ & Sig. \\
\hline & B & Std. Error & Beta & & \\
\hline (Constant) & .277 & .222 & & 1.251 & .214 \\
\hline PesanPersuasif & .875 & .055 & .828 & 15.850 & .000 \\
\hline
\end{tabular}

Hasil uji $\mathrm{T}$ pada variabel $\mathrm{X}$ adalah Ho ditolak dan Ha diterima, artinya terdapat pengaruh signifikan pesan persuasif media sosial terhadap brand resonance. Pengaruh signifikan tersebut juga berlaku terhadap populasi Starbucks seluruhnya

\section{Simpulan}

Perusahaan yang memanfaatkan media sosial Line untuk memasarkan produknya, mempunyai pengaruh yang sangat kuat terhadap pembentukan brand resonance. Hal ini dibuktikan melalui penelitian ini, pesan persuasif media sosial Line terhadap brand resonance sebesar $77.8 \%$ dan sisanya sebesar $22.2 \%$ yang mempengaruhi brand resonance. Penelitian ini menunjukkan terdapat pengaruh signifikan dan positif pesan persuasif media sosial Line terhadap brand resonance. Penulis berharap agar penelitian ini menjadi acuan bagi praktisi komunikasi pemasaran dan public relations dalam meningkatkan brand resonance melalui pesan persuasif media sosial Line. 
Andini Putri Apriani, Roswita Oktavianti: Pengaruh Pesan Persuasif Media Sosial LINE Terhadap Brand Resonance (Survei Pelanggan Starbucks Tangerang)

\section{Daftar Pustaka}

Ghozali, Imam. (2006). Aplikasi Analisis Multivariate dengan Program SPSS. Semarang: BP Undip.

Haryani, Sri. (2001). Komunikasi Bisnis. Jakarta: AMP YKPN.

Keller, Kevin L. (2013). Strategic Brand Management ; Building, Measurin, and Managing Brand Equity. Fourth Edition Harlow, English: Pearson Education Inc.

Priansa, Donni Juni. (2017). Komunikasi Pemasaran Terpadu. Jakarta: Pustaka Setia. Purwanto. (2010). Evaluasi Hasil Belajar. Yogyakarta: Pustaka Belajar.

Ritonga. M Jamiluddin. (2005). Tipologi Pesan Persuasif. Jakarta: PT. Indeks.

Sugiyono. (2010). Metode Penelitian Kuantitatif dan R\&D. Bandung: ALFABET.

Oktavianti, Roswita \& Riris Loisa. Penggunaan Media Sosial Sesuai Nilai Luhur

Budaya di Kalangan Siswa SMA. Jurnal Pengabdian Kepada Masyarakat, 3 (1), 86-95. 